\title{
Restaurantes self-service: segurança e qualidade sanitária dos alimentos servidos
}

\author{
Self-service restaurants: food safety \\ and sanitary quality
}

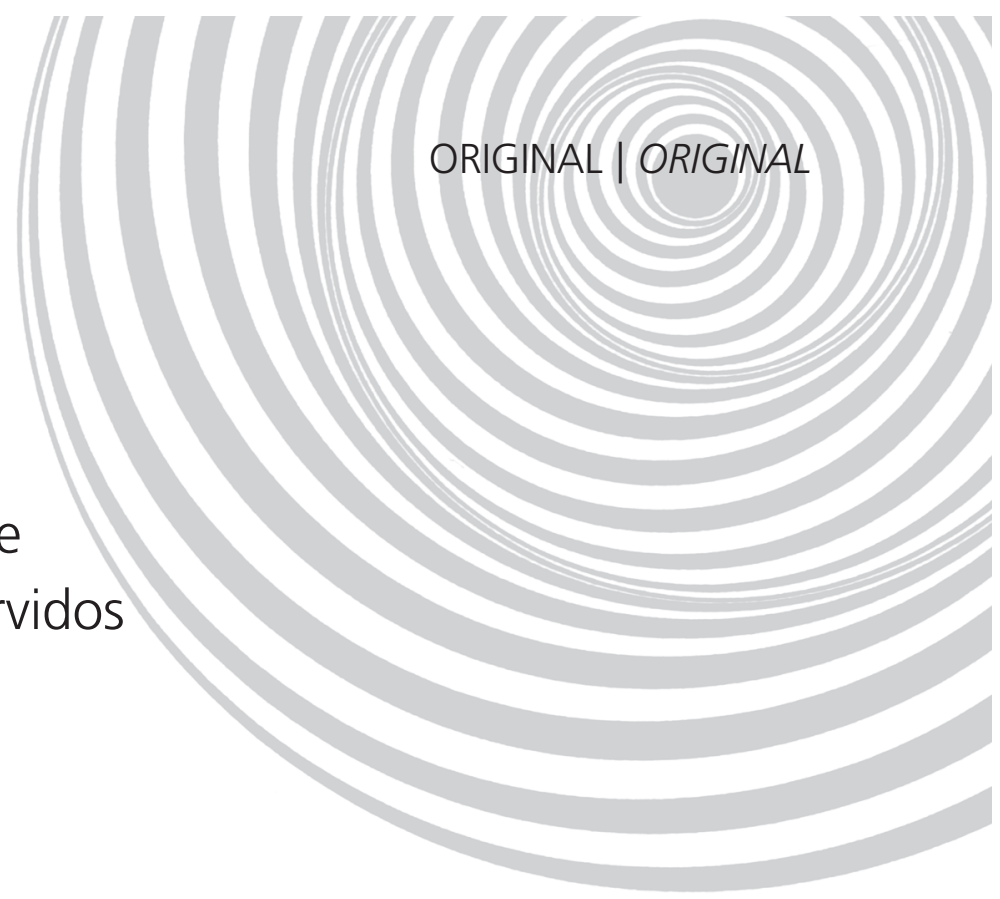

Mariana Gardin ALVES ${ }^{1}$

Mariko UENO ${ }^{1}$

\section{R E S U M O}

\section{Objetivo}

Esse trabalho teve por objetivo avaliar a temperatura e a qualidade sanitária de alimentos servidos nos balcões de distribuição em restaurantes self-service no município de Taubaté (SP), com vistas à discussão da segurança alimentar.

\section{Métodos}

Foram coletadas quatro amostras, sendo dois alimentos quentes e dois alimentos frios de 16 restaurantes; antes da coleta mediu-se a temperatura dos alimentos expostos nos balcões de distribuição. As amostras foram analisadas quanto aos seguintes parâmetros: contagem de bactérias aeróbias mesófilas, determinação de coliformes a $35^{\circ} \mathrm{C}$ e a $45^{\circ} \mathrm{C}$, contagem de Staphylococcus coagulase positiva e detecção de Salmonella.

\section{Resultados}

Cinquenta e seis $(87,5 \%)$ alimentos estavam em temperaturas inadequadas, alimentos frios expostos em temperaturas acima de $10^{\circ} \mathrm{C}$ e alimentos quentes abaixo de $60^{\circ} \mathrm{C}$. Bactérias aeróbias mesófilas em contagem acima de $10^{6} \mathrm{UFC} / \mathrm{g}$ foram detectadas em $11 \%$ das amostras e coliformes a $35^{\circ} \mathrm{C}$ e coliformes a $45^{\circ} \mathrm{C}$ foram detectadas em $76,6 \%$ e $43,7 \%$ das amostras, respectivamente. Dois alimentos, sendo um frio e um quente, provenientes de um mesmo restaurante, apresentaram contagem de Staphylococcus coagulase positivo acima de $10^{4} \mathrm{UFC/g}$. Todas as amostras apresentaram ausência de Salmonella.

\section{Conclusão}

A manutenção dos alimentos servidos, nos balcões de distribuição, em temperaturas abusivas e a presença de microrganismos indicadores de qualidade sanitária em número elevado comprometem a segurança e podem colocar em risco a saúde dos consumidores, em restaurantes self-service. Os instrumentos utilizados demonstraram-se como ferramentas importantes de avaliação da segurança das refeições servidas.

Termos de indexação: Inspeção de alimentos. Qualidade de alimentos. Restaurantes. Segurança alimentar.

\footnotetext{
${ }^{1}$ Universidade de Taubaté, Instituto Básico de Biociências. Av. Tiradentes, 500, Campus Bom Conselho, 12030-180, Taubaté, SP, Brasil. Correspondência para/Correspondence to: M. UENO. E-mail: <mariueno@unitau.br>.
} 
574 | M.G. ALVES \& M. UENO

\section{A B S T R A C T}

\section{Objective}

This work aimed to assess the temperature and sanitary quality of the foods available on the buffet table of self-service restaurants located in the city of Taubaté (SP), in order to discuss food safety.

\section{Methods}

Four samples, two of cold dishes and two of hot dishes, were collected from each of 16 restaurants. The temperature of the foods on the buffet table was measured before the sample was taken. The following parameters were investigated for each sample: aerobic mesophilic bacteria count, determination of coliforms at $35^{\circ} \mathrm{C}$ and $45^{\circ} \mathrm{C}$, coagulase-positive Staphylococcus count and presence of Salmonella.

\section{Results}

The temperature of 56 (87.5\%) foods was inadequate: cold dishes were kept above $10^{\circ} \mathrm{C}$ and hot dishes were kept below $60^{\circ} \mathrm{C}$. Aerobic mesophilic bacteria counts above $10^{6} \mathrm{CFU} / \mathrm{g}$ were detected in $11 \%$ of the samples, coliforms at $35^{\circ} \mathrm{C}$ in $76.6 \%$ and coliforms at $45^{\circ} \mathrm{C}$ in $43.7 \%$. Two foods, one cold and one hot, both from the same restaurant, had a coagulase-positive Staphylococcus count above $10^{4}$ CFU/g. Salmonella was not found in any of the samples.

\section{Conclusion}

Keeping the foods available on buffet tables under incorrect temperatures and a high count of microorganisms that indicate poor sanitary quality of the food can compromise safety and jeopardize the customer's health. The instruments used in this study proved to be important tools for assessing food safety.

Indexing terms: Food inspection. Food quality. Restaurants. Food safety.

\section{N T R O D U Ç Ã O}

A vida moderna imprimiu um ritmo acelerado ao cotidiano dos indivíduos, causando mudanças nos hábitos de vida e alimentares, modificado por diversos fatores, como o aumento da jornada de trabalho, dificuldades em locomoção, aumento da população em centro urbano e principalmente o aumento da utilização da mão de obra feminina. Com isto, torna-se cada vez maior o número de refeições feitas fora do domicílio, gerando um aumento de restaurantes, principalmente o do tipo self-service ${ }^{1}$. Essa modalidade visa uma clientela com limitação de tempo e/ou de orçamento para suas refeições e normalmente encontram-se nos centros comerciais das cidades².

Os alimentos servidos nos restaurantes têm como fator negativo a insegurança, devido à contaminação, podendo causar doenças veiculadas por alimentos ${ }^{3,4}$. A qualidade de uma refeição é influenciada por inúmeros fatores, entre eles a qualidade da matéria-prima, a higiene dos utensílios utilizados, manipuladores envolvidos no processo, bem como o monitoramento de parâ- metros, como tempo e temperatura ${ }^{5,6}$. A temperatura é um fator importante para a população microbiológica presente nos alimentos, por isso a distribuição deve ocorrer com controle de tempo e temperatura para minimizar a multiplicação microbiana e proteger de novas contaminações ${ }^{7}$.

Os perigos microbiológicos são as principais causas de contaminação dos alimentos e os manipuladores constituem a origem do problema e são grandes responsáveis pela sua contaminação microbiológica ${ }^{8}$. O controle da contaminação por micro-organismos deterioradores e patogênicos nos serviços de alimentação é difícil e complexo devido à grande variedade de alimentos preparados. Há também o risco potencial de os manipuladores de alimentos serem portadores assintomáticos de microrganismos patogênicos ${ }^{9-11}$.

Para evitar as doenças de origem alimentar, devem-se enfatizar as situações que visem à prevenção de agentes patogênicos e as condições de maior risco e, para assegurar que os alimentos sejam preparados de modo a garantir a segurança do consumidor, devem ser adotadas medidas de 
prevenção e controle em todas as etapas da cadeia produtiva ${ }^{12}$. Para White et al. ${ }^{13}$ deve-se oferecer treinamento aos manipuladores para aperfeiçoar tanto sua higiene pessoal quanto a higiene ambiental e dos alimentos. Nesse sentido, o controle higiênico-sanitário dos alimentos constitui fator preponderante para prevenção das doenças de origem alimentar ${ }^{14,15}$.

Assim, a produção, preparação, distribuição e armazenamento de alimentos, com segurança, são atividades que exigem cuidados especiais com o ambiente de trabalho, os equipamentos e utensílios, os alimentos propriamente ditos, os manipuladores de alimentos, com as instalações sanitárias e com o controle de pragas, entre outros ${ }^{16}$.

Avaliar as condições sanitárias dos alimentos prontos para o consumo, servidos nos restaurantes self-service, é de grande importância para a avaliação das condições de preparo e distribuição. Neste sentido foi realizado um estudo, com a finalidade de conhecer a situação dos alimentos nos balcões de distribuiç̧ão, em restaurantes self-service, localizados na região central do município de Taubaté (SP). Esta iniciativa se faz necessária para a obtenção de informações, que podem ser utilizadas por órgãos da Vigilância Sanitária como indicadores de condições higiênico-sanitárias das refeições servidas.

\section{M É T O D O S}

Fizeram parte desse estudo, 16 restaurantes self-service que representam o total desta tipologia, na região central do município de Taubaté (SP). Em cada restaurante foram coletadas quatro amostras, sendo dois alimentos quentes e dois alimentos frios. Para os alimentos quentes deu-se preferência àqueles à base de carne e para os frios àqueles que continham maionese, e na ausência destes, àqueles que exigiram mais manipulação pós-cocção.

Antes da coleta mediu-se a temperatura dos alimentos expostos nos balcões com termô- metro digital tipo espeto WT1, com faixa de temperatura entre $-50^{\circ} \mathrm{C} \mathrm{a}+300^{\circ} \mathrm{C}$. Os parâmetros de temperatura foram aqueles descritos na Portaria CVS no 6 de 10 de março de 19997.

Os alimentos foram coletados com o talher comum, transferidos para sacos plásticos esterilizados, e transportados em caixas isotérmicas ao laboratório de microbiologia da Universidade de Taubaté (Unitau).

As análises microbiológicas das 64 amostras foram iniciadas em tempo menor que duas horas após a coleta, seguiu-se a metodologia descrita por Silva et al. ${ }^{17}$ Para a determinação de coliformes a $35^{\circ} \mathrm{C}$ e a $45^{\circ} \mathrm{C}$ utilizou-se a técnica no Número Mais Provável, a confirmação de a $45^{\circ} \mathrm{C}$ foi realizada por meio da inoculação em Agar Levine Eosina Azul de Metileno (EMB). Colônias típicas foram selecionadas para as provas bioquímicas de Indol, vermelho de metila, Voges Proskauer e citrato (IMViC). A contagem total de bactérias aeróbias mesófilas foi realizada pela técnica de contagem padrão em placas. Para a contagem de Staphylococcus coagulase positiva utilizou-se método de contagem em placa em ágar Baird-Parker, colônias típicas foram selecionadas para as provas de catalase e coagulase. A detecção de Salmonella foi realizada por método tradicional presença/ausência; a técnica consta de pré-enriquecimento em caldo lactosado, enriquecimento em caldo tetrationato, plaqueamento diferencial em Agar Entérico Hektoen (HE), Agar Xilose Lisina Desoxicolato (XLD) e Agar Bismuto Sulfito (BS).

\section{RES U L T A D OS}

A temperatura dos alimentos quentes nos balcões de distribuição variou de 33 a $71,2^{\circ} \mathrm{C}$ (Tabela 1$)$, sete $(21,9 \%)$ estavam acima de $60^{\circ} \mathrm{C}$, considerada segura para o controle microbiano; vinte $(62,5 \%)$ estavam na faixa de 40 a $59,9^{\circ} \mathrm{C}$, nessa faixa os alimentos podem ficar expostos por até três horas, e cinco $(15,6 \%)$ amostras estavam abaixo de $40^{\circ} \mathrm{C}$. 
A temperatura dos alimentos frios variou de 9,7 a $41,7^{\circ} \mathrm{C}$ (Tabela 2), sendo que apenas um $(3,1 \%)$ estava em temperatura ideal, $14(43,7 \%)$ estavam entre 10 e $21^{\circ} \mathrm{C}$, nesta faixa os alimentos podem permanecer por duas horas e $17(53,1 \%)$ estavam em temperatura acima de $21^{\circ} \mathrm{C}$.

Os resultados das análises microbiológicas dos alimentos quentes e alimentos frios e as temperaturas registradas podem ser observados na Tabelas 1 e 2, respectivamente.

\section{I S C U S S Ã O}

Apenas $22 \%$ dos alimentos quentes estavam em temperatura que confere segurança aos consumidores, acima de $60^{\circ} \mathrm{C}$, esse resultado foi semelhante ao de Momesso et al..$^{18}$ que encontraram 20\% dos alimentos com temperatura acima de $60^{\circ} \mathrm{C}$. Por outro lado Chesca et al. ${ }^{19}$ observaram que $100 \%$ dos alimentos quentes estavam acima de $60^{\circ} \mathrm{C}$. Para Brugalli et al..$^{20}$ os alimentos como arroz e feijão, em balcões de distribuição,

Tabela 1. Resultados das análises microbiológicas e temperatura na distribuição, de alimentos quentes servidos em restaurantes selfservice no município de Taubaté (SP).

\begin{tabular}{|c|c|c|c|c|c|c|}
\hline Amostra & $\begin{array}{c}\text { Bactérias aeróbias } \\
\text { mesófilas UFC/g }\end{array}$ & $\begin{array}{l}\text { Coliformes a } \\
35^{\circ} \mathrm{C} \mathrm{NMP/g}\end{array}$ & $\begin{array}{l}\text { Coliformes a } \\
45^{\circ} \mathrm{C} \mathrm{NMP/g}\end{array}$ & $\begin{array}{c}\text { Staphylococcus coagulase } \\
\text { positivo UFC/g }\end{array}$ & $\begin{array}{l}\text { Salmonella } \\
\text { sp. }\end{array}$ & $\mathrm{T}^{\circ} \mathrm{C}$ \\
\hline Frango & $3,35 \times 10^{2}$ & $<0,3$ & $<0,3$ & $<100$ & - & 40 a 59,9 \\
\hline Salsicha ao sugo & $4,5 \times 10^{2}$ & $<0,3$ & $<0,3$ & $<100$ & - & 40 a 59,9 \\
\hline Linguiça acebolada & $4,7 \times 10^{4}$ & $<0,3$ & $<0,3$ & $<100$ & - & $<40$ \\
\hline Carne assada & $5,9 \times 10^{4}$ & $<0,3$ & $<0,3$ & $<100$ & - & $<40$ \\
\hline Bife role & $8,1 \times 10^{4}$ & $<0,3$ & $<0,3$ & $<100$ & - & $>60$ \\
\hline Linguiça frita & $7,3 \times 10^{3}$ & 0,4 & 0,4 & $<100$ & - & 40 a 59,9 \\
\hline Carne assada & $6,4 \times 10^{3}$ & 4,3 & $<0,3$ & $<100$ & - & 40 a 59,9 \\
\hline Bife à milanesa & $2,6 \times 10^{2}$ & $<0,3$ & $<0,3$ & $<100$ & - & $<40$ \\
\hline Moela & $1,02 \times 10^{4}$ & 46 & 0,7 & $<100$ & - & 40 a 59,9 \\
\hline $\begin{array}{l}\text { Rocambole recheado } \\
\text { com mussarela }\end{array}$ & $1,03 \times 10^{6}$ & $\geq 240$ & 15 & $5,7 \times 10^{4}$ & - & 40 a 59,9 \\
\hline Cubos carne cozido & $4 \times 10^{2}$ & 110 & $<0,3$ & $<100$ & - & $>60$ \\
\hline Bife acebolado & $2 \times 10^{2}$ & $<0,3$ & $<0,3$ & $<100$ & - & $>60$ \\
\hline Carne assada & $6,8 \times 10^{2}$ & 1,6 & $<0,3$ & $<100$ & - & 40 a 59,9 \\
\hline Linguiça frita & $5,3 \times 10^{3}$ & $<0,3$ & $<0,3$ & $<100$ & - & 40 a 59,9 \\
\hline Filé de frango & $3,1 \times 10^{3}$ & 2,3 & $<0,3$ & $<100$ & - & 40 a 59,9 \\
\hline Carne assada & $1,08 \times 10^{4}$ & 4,3 & $<0,3$ & $<100$ & - & 40 a 59,9 \\
\hline Carne de panela & $9,3 \times 10^{4}$ & $\geq 240$ & 0,7 & $<100$ & - & $>60$ \\
\hline Salsicha ao sugo & $4,45 \times 10^{3}$ & $<0,3$ & $<0,3$ & $<100$ & - & 40 a 59,9 \\
\hline Chester & $8,75 \times 10^{3}$ & 110 & 0,9 & $<100$ & - & 40 a 59,9 \\
\hline Carne de panela & $4,05 \times 10^{3}$ & $<0,3$ & $<0,3$ & $<100$ & - & $>60$ \\
\hline Bife acebolado & $6,84 \times 10^{3}$ & $<0,3$ & $<0,3$ & $<100$ & - & 40 a 59,9 \\
\hline Strogonoff de frango & $5,7 \times 10^{3}$ & $<0,3$ & $<0,3$ & $<100$ & - & 40 a 59,9 \\
\hline Filé de frango & $5,85 \times 10^{3}$ & 24 & 1,5 & $<100$ & - & 40 a 59,9 \\
\hline $\begin{array}{l}\text { Carne de panela com ba- } \\
\text { tata e cenoura }\end{array}$ & $7 \times 10^{2}$ & 0,9 & $<0,3$ & $<100$ & - & 40 a 59,9 \\
\hline $\begin{array}{l}\text { Lagarto recheado } \\
\text { com linguiça }\end{array}$ & $9,3 \times 10^{4}$ & 9,3 & 2,1 & $<100$ & - & 40 a 59,9 \\
\hline Almôndegas & $5,1 \times 10^{6}$ & 4,3 & $<0,3$ & $<100$ & - & 40 a 59,9 \\
\hline Dobradinha & $5,25 \times 10^{2}$ & $<0,3$ & $<0,3$ & $<100$ & - & $>60$ \\
\hline Bisteca suína & $5,6 \times 10^{4}$ & 0,4 & $<0,3$ & $<100$ & - & $<40$ \\
\hline Carne assada & $3,14 \times 10^{4}$ & $<0,3$ & $<0,3$ & $<100$ & - & $>60$ \\
\hline Filé de frango empanado & $9,7 \times 10^{4}$ & 46 & 0,4 & $<100$ & - & 40 a 59,9 \\
\hline Carne assada & $5,7 \times 10^{3}$ & 46 & $<0,3$ & $<100$ & - & 40 a 59,9 \\
\hline Filé de frango grelhado & $3 \times 10^{3}$ & $<0,3$ & $<0,3$ & $<100$ & - & $<40$ \\
\hline
\end{tabular}

- : Ausente. 
Tabela 2. Resultado das análises microbiológicas e temperatura na distribuição, de alimentos frios servidos em restaurantes self-service no município de Taubaté (SP).

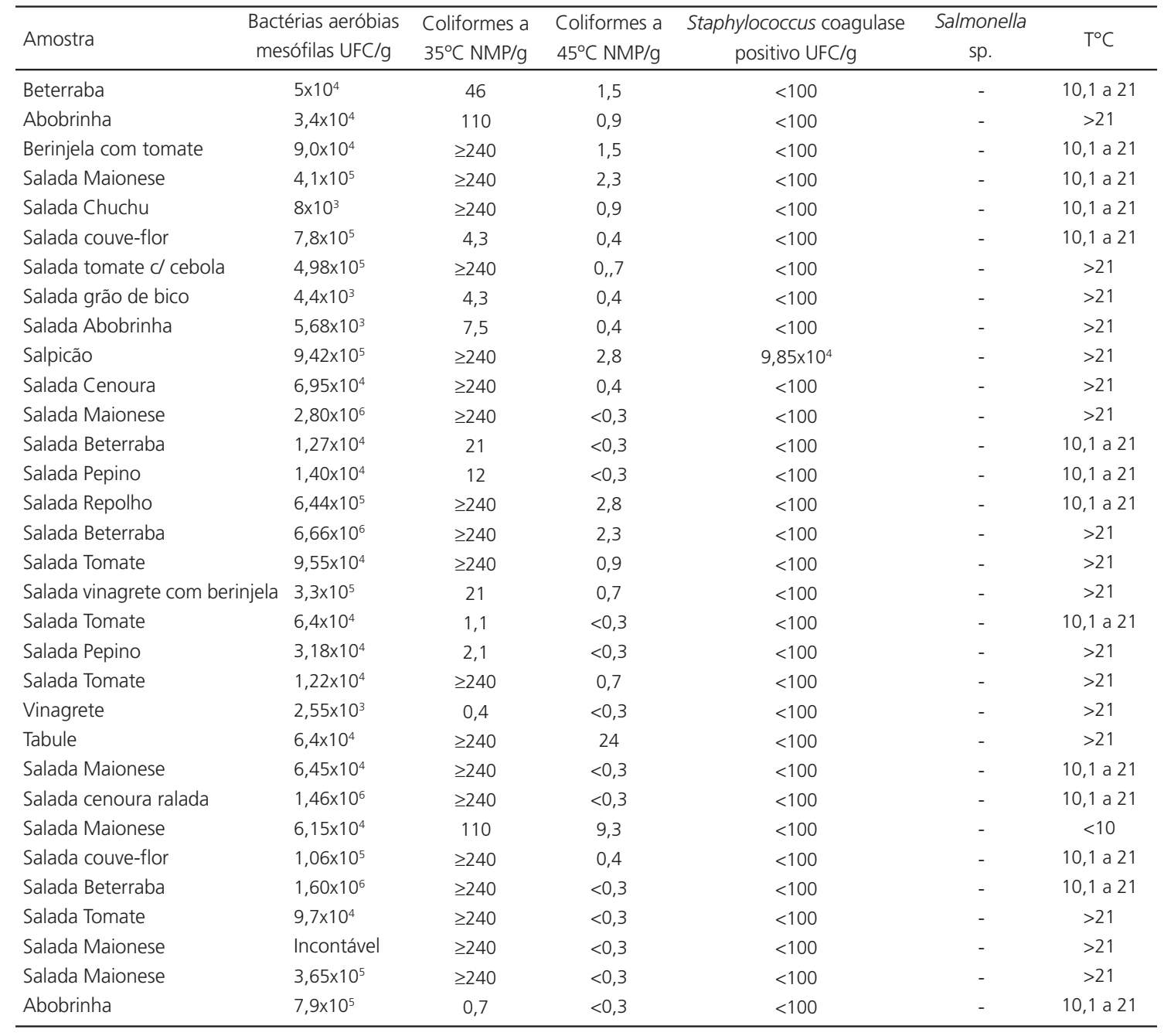

-: Ausente.

encontravam-se, na maioria das vezes, em temperatura acima de $60^{\circ} \mathrm{C}$, o que não ocorria com carnes e as guarnições.

Considerando a temperatura dos alimentos no balcão de distribuição, nesse estudo, apenas 3,1\% dos alimentos encontrava-se em temperatura adequada. Resultados similares foram encontrados por Momesso et al. ${ }^{19}$ que observaram que 3,7\% das amostras estava em temperatura considerada segura. Alimentos frios expostos em temperatura acima do permitido podem ter como principal causa a falta de equipamentos adequados de refrigeração, assim como a falta de conscientização dos manipuladores em refrigerar adequadamente os alimentos. Na distribuição, os alimentos frios podem ser mantidos a $10^{\circ} \mathrm{C}$ por até quatro horas, ou entre 10 e $21^{\circ} \mathrm{C}$ por duas horas, e acima dessa temperatura, os alimentos devem ser desprezados ${ }^{8}$.

As análises de coliformes a $35^{\circ} \mathrm{C}$ nos alimentos evidenciaram que 49 (76,6\%) amostras apresentaram contaminação por esses micro-organismos. Embora a legislação brasileira não esta-beleça limites para coliformes a $35^{\circ} \mathrm{C}$, altos níveis indicam condições higiênico-sanitárias insatis-fatórias. Contagens de coliformes a $35^{\circ} \mathrm{C}$ 
578 | M.G. ALVES \& M. UENO

maior que 240NMP/g foram registrados em 19 alimentos frios, destes todos estavam em temperatura superior a $10^{\circ} \mathrm{C}$, sendo que dez estavam em tem-peratura superior a $21^{\circ} \mathrm{C}$; e em dois alimentos quentes, estes estavam em temperatura abaixo de $60^{\circ} \mathrm{C}$. Azerêdo et al. ${ }^{21}$ encontraram $15,3 \%$ das amostras de alimentos frios positivas para coliformes a $35^{\circ} \mathrm{C}$ e os valores variaram de 4 a $>1100 \mathrm{NMP} / \mathrm{g}$.

Foi detectada presença de coliformes a $45^{\circ} \mathrm{C}$, com confirmação de Escherichia coli, em $19(70,4 \%)$ alimentos frios, dentre esses 12 $(63,2 \%)$ estavam em temperatura acima de $21^{\circ} \mathrm{C}$; e em oito $(29,6 \%)$ alimentos quentes, os quais estavam expostos em temperatura abaixo de $60^{\circ} \mathrm{C}$, sendo que um $(12,5 \%)$ estava abaixo de $40^{\circ} \mathrm{C}$. Em 37 (57,8\%) alimentos encontrou-se resultado $<0,3 \mathrm{NMP} / \mathrm{g}$. Nenhuma amostra apresentou valor superior ao permitido pela legislação ${ }^{22}$ que estabelece contagem máxima de $2 \times 10 \mathrm{NMP} / g$ para coliformes a $45^{\circ} \mathrm{C}$, diferente de Costa et al. ${ }^{23}$ que encontraram valores acima do permitido para saladas de vegetais em Palmas (TO). Contagem de coliformes a $45^{\circ} \mathrm{C}$ acima do padrão também foi detectada em 12 (92,3\%) das amostras de hortaliças e 9 (64,3\%) das amostras de frutas servidas em restaurante self-service ${ }^{24}$.

Com relação às bactérias aeróbias mesófilas, 7 (11\%) amostras apresentaram contagem maior ou igual a $10^{6} \mathrm{UFC} / \mathrm{g}$, sendo cinco alimentos frios e dois alimentos quentes. Azerêdo et al. ${ }^{21}$ encontraram contagens entre $8 \times 10^{2}$ a $8 \times 10^{5} \mathrm{UFC} / \mathrm{g}$. A RDC $n^{\circ} 12$ de 2 de janeiro de $2001^{22}$ não apresenta limites para contagens de bactérias aeróbias mesófilas em alimentos prontos para consumo, alimentos servidos em restaurantes e similares, entretanto, contagens acima de $10^{6} \mathrm{UFC} / \mathrm{g}$ podem indicar exposição à contaminação ambiental, permanência por tempo prolongado em temperatura abusiva, armazenamento em temperatura inadequada de refrigeração, bem como manipulação excessiva.

Os sete alimentos com contagem de bactérias aeróbias mesófilas maior ou igual a $10^{6}$ UFC estavam expostos em temperaturas abusivas.
Dentre os alimentos frios, o salpicão estava acima de $21^{\circ} \mathrm{C}$. Os dois alimentos quentes estavam abaixo de $60^{\circ} \mathrm{C}$, um dos alimentos era rocambole de carne recheado com mussarela.

Duas amostras $(6,2 \%)$, provenientes do mesmo restaurante, apresentaram Staphylococcus coagulase positivo acima do limite de $10^{3} \mathrm{UFC} / \mathrm{g}^{22}$, sendo um alimento quente, o rocambole de carne recheado com mussarela com $5,7 \times 10^{4} \mathrm{UFC} / \mathrm{g}$, e

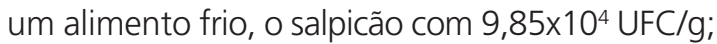
semelhante ao estudo de Rossi et al. ${ }^{25}$ que encontraram 7,1\% das amostras de pratos quentes em restaurantes self-service em Uberlândia, MG, com contagem acima do padrão.

O rocambole estava à temperatura de $57,8^{\circ} \mathrm{C}$; apresentou $15 \mathrm{NMP} / \mathrm{g}$ de coliformes a $45^{\circ} \mathrm{C}$; coliformes a $35^{\circ} \mathrm{C}$ maior que $240 \mathrm{NMP} / \mathrm{g} \mathrm{e}$ $1,03 \times 10^{6} \mathrm{UFC} / \mathrm{g}$ de bactérias aeróbias mesófilas. O salpicão estava a $28,3^{\circ} \mathrm{C}$, também apresentou contaminação por coliformes a $45^{\circ} \mathrm{C}$ em nível de 2,8NMP/g; coliformes a $35^{\circ} \mathrm{C}$ maior que

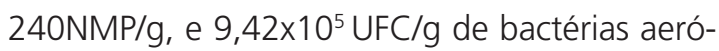
bias mesófilas, indicando qualidade sanitária insatisfatória. A relação entre as temperaturas medidas e as contagens dos micro-organismos indicadores de qualidade sanitária desses dois alimentos mostra que a temperatura dos alimentos na distribuição tem um papel relevante na segurança dos alimentos servidos.

Pode-se inferir que rocambole e salpicão, poderiam ter sido contaminados por Staphylococcus coagulase positivo durante a manipulação. A presença de $S$. aureus nos alimentos é interpretada como indicativo de contaminação proveniente dos manipuladores, esse tipo de bactéria pode causar toxi-infecções veiculadas por alimentos se as boas práticas de higiene não forem implementadas e seguidas $^{26}$.

No presente estudo $100 \%$ das amostras apresentaram ausência de Salmonella, resultado idêntico ao de Damasceno et al.27; Zoli et al..28. Entretanto, Momesso etal. ${ }^{21}$ detectaram Salmonella sp. em quatro amostras, bisteca suína, salsicha e salada de maionese, sendo que, neste último, maionese industrializada foi utilizada na prepa- 
ração, sugerindo que a contaminação de Samonella poderia ter sido originada por contaminação cruzada. Barreto \& Vieira ${ }^{29}$ afirmaram que atualmente a Salmonella é um dos micro-organismos mais frequentemente envolvido em casos de surtos de doenças de origem alimentar, em diversos países, inclusive no Brasil.

Pudemos concluir que os restaurantes self service analisados apresentam falhas que podem comprometer a higiene dos alimentos e em consequência acarretar riscos à saúde. A Resolução RDC $n^{\circ} 216$, de 15 de setembro de $2004^{30}$ determina que o manipulador deve proceder de maneira adequada e segura na manipulação, preparo, acondicionamento, armazenamento, transporte e exposição dos alimentos em restaurantes entre outros.

A temperatura dos alimentos dispostos na distribuição encontrava-se inadequada, em vários restaurantes, tanto para os alimentos quentes como para os frios, esta irregularidade é considerada crítica na oferta de alimento seguro, podendo comprometer a saúde dos consumidores. Apesar de existirem regras de higiene e manuseio dos alimentos em restaurantes, ainda existem riscos para a saúde associados a alimentos servidos em restaurante self-service, visto que muitos manipuladores não as seguem. Portanto é necessário ter cuidado com a qualidade dos serviços prestados por estes estabelecimentos, principalmente no que se refere à higiene dos manipuladores, bem como à higienização de equipamentos e utensílios.

A contaminação via alimentos é uma das maiores causas de doenças e, consequentemente, internações hospitalares, em todo o mundo. Vários são os agentes patogênicos que podem ser veiculados por alimentos contaminados, e causar doenças. Em restaurantes self-service a contaminação geralmente decorre do modo inapropriado na manipulação e distribuição dos alimentos prontos para consumo.

Alguns alimentos apresentaram contagem de Staphylococcus coagulase positiva, em níveis maiores que os permitidos pela legislação brasi- leira. As altas contagens de micro-organismos potencialmente patogênicos em alguns alimentos é resultado da soma de fatores que incluem desde questões físico-estruturais, manipulação inadequada dos alimentos, bem como exposição excessiva do alimento ao ambiente e ao comensal, em restaurantes self-service. Tais achados podem contribuir para alertar as autoridades sanitárias para o risco potencial, de alimentos servidos em restaurantes self-service.

\section{COLABORADORES}

M.G. ALVES participou da elaboração do projeto, da coleta dos dados e da análise e interpretação dos resultados. M. UENO participou da elaboração do projeto, da interpretação dos resultados e da redação do artigo.

\section{REFERÊ NCIAS}

1. Yamamoto DC, Marlet EF, Silva FR, Santos LCCA. Caracterização das condições higiênico-sanitárias dos restaurantes 'fast food' de dois 'shoppingcenters' em diferentes regiões do município de São Paulo. Hig Aliment. 2004; 18(122):14-20.

2. Nunes IFS, Ferreira GP, Albuquerque WF. Perfil microbiológico dos microrganismos causadores de DTAs em restaurantes "self-services" na cidade de Teresina-PI. Hig Aliment. 2002; 16(102-103):59-62.

3. Lima JL, Oliveira LF. O crescimento do restaurante self-service: aspectos positivos e negativos para o consumidor. Hig Aliment. 2005; 19(128):45-53.

4. Jones TF, Angulo FJ. Eating in restaurants: a risk factor for foodborne disease? Clin Infect Dis. 2006; 43(10):1324-8.

5. Kawasaki VM, Cyrillo DC, Machado FMS. Sistematização de dados de tempo e temperatura para avaliação da segurança higiênico-sanitária, em unidades de alimentação e nutrição. Hig Aliment. 2007; 21(149):35-40.

6. Emrich NE, Viçosa AL, Cruz AG. Boas práticas de fabricação em cozinhas hospitalares: um estudo comparativo. Hig Aliment. 2006; 20(144):15-24.

7. São Paulo. Secretária de Estado de Saúde. Portaria $n^{\circ} 6$, de 10 de março de 1999. Regulamento técnico que estabelece os parâmetros e critérios para o controle higiênico-sanitário em estabelecimentos de alimentos. Diário Oficial da União; 1999. 
8. Souza LHL. A manipulação inadequada dos alimentos: fator de contaminação. Hig Aliment. 2006; 20(146):32-9.

9. Pinto UM, Cardoso RR, Vanetti MCD. Detecção de Listeria, Salmonella e Klebsiella em serviço de alimentação hospitalar. Rev Nutr. 2004; 17(3):319-26. doi: 10.1590/S1415-52732004000300005.

10. Peretti APR, Spezia DS, Araújo WMC. Certificação de qualidade no segmento de "food service". Hig Aliment. 2004; 18(121):14-8.

11. Mitchel RE, Fraser AM, Bearon LB. Preventing foodborne illness in food service establishments: broadening the framework for intervention and research on safe food handling behaviors. Int J Environ Health Res. 2007; 17(1):9-24.

12. Genta TMS, Maurício AA, Matioli G. Avaliação das boas práticas através de "check-list" aplicado em restaurantes "self-service" da região central de Maringá, estado do Paraná. Acta Sci Health Sci. 2005; 27(2):151-6.

13. White HJ, Vilela DC, Krepp ACM, Goulart RMQC. Análise microbiológica das mãos dos manipuladores envolvidos no preparo de dietas enterais do hospital de Itajubá, MG. Nutr Pauta. 2005; 70:46-9.

14. Valejo FAM, Andrés CR, Mantovan FB, Rister GP, Santos GD, Andrade FF. Vigilância sanitária: avaliação e controle da qualidade dos alimentos. Hig Aliment. 2003; 17(106):16-21.

15. Neta RXB, Holland N, Chaves KSFS, Damasceno KSFSC. Análise dos perigos e pontos críticos de controle durante o preparo da alface servida no restaurante universitário da UFRN. Hig Aliment. 2004; 8(126-127):36-43.

16. Mesquita MO, Daniel AP, Saccol ALF, Milani LIG, Fries LLM. Qualidade Microbiológica no processamento do frango assado em unidade de alimentação e nutrição. Ciênc Tecnol Aliment. 2006; 26(1): 198-203.

17. Silva N, Junqueira VCA, Silveira NFA, Taniwaki MH, Santos RFS, Gomes RAF. Manual de métodos de análise microbiológica de alimentos. $3^{\text {a }}$ ed. São Paulo: Varela; 2007.

18. Momesso AP, Matté MH, Germano PML. Avaliação das condições higiênico-sanitárias, por quilo, do município de São Paulo, durante o período de distribuição de refeições. Hig Aliment. 2005; 19(136): 81-9.

19. Chesca AC, Caetano AM, Leite APC, Polveiro AM, Terra AD, Lyra FS, et al. Avaliação das temperaturas de pistas frias e quentes em restaurantes da cidade de Uberaba, MG. Hig Aliment. 2001; 15(87):38-43.

20. Brugalli A, Pinto JM, Tondo EC. Análise de perigos e pontos críticos de controle para garantir a segu- rança alimentar em restaurante da Universidade Federal do Rio Grande do Sul. Hig Aliment. 2002; 16(101):15-9.

21. Azerêdo GA, Conceição ML, Stamford TLM. Qualidade higiênico-sanitária das refeições em um restaurante universitário. Hig Aliment. 2004; 18(125): 74-8.

22. Brasil. Ministério da Saúde. Secretaria da Vigilância Sanitária. Resolução RDC n 12, 2 de janeiro de 2001. Regulamento técnico sobre os padrões microbiológicos para alimentos. Diário Oficial da República Federativa do Brasil. 2001; 10 jan; Seção 1, p.45-53.

23. Costa AA, Souza Júnior VM, Coelho AFS. Avaliação microbiológica de saladas de vegetais seridas em restaurantes self-service na ciade de Palmas, TO. Hig Aliment. 2008; 22(159):27-32.

24. Palú AP, Tibana A, Teixeira LM, Miguel MAL, Pyrrho AS, Lopes HR. Avaliação microbiológica de frutas e hortaliças frescas, servidas em restaurantes "self-service" privados, da Universidade do Rio de Janeiro. Hig Aliment. 2002; 16(100):67-74.

25. Rossi DA, Zardini F, Barros JJC, Santos JBF. Coliformes termotolerantes e Staphylococcus coagulase positiva em pratos quentes servidos em restaurantes self-service de Uberlândia, MG. Hig Aliment. 2005; 19(136):90-5.

26. Maistro LC, Hirayama KB, Martinelli RM. Controle de qualidade higiênico-sanitária no processo de produção de alimentos através da detecção de Staphylococcus aureus em mãos de manipuladores. Nutr Pauta. 2005; 75:38-42.

27. Damasceno KSFSC, Alves MA, Freire IMG, Torres GF, Ambrósio CLB, Guerra NG. Condições higiênico-sanitárias de "self-service" do entorno da UFPE e das saladas cruas por eles servidas. Hig Aliment. 2002; 16(102/103):74-8.

28. Zoli JA, Negrete HRC, Oliveira TCRM. Avaliação da contaminação por Staphylococcus aureus e Salmonella spp., de maionese de batata comercializada em Londrina, PR. Hig Aliment. 2002; 16(95):62-71.

29. Barreto NSE, Vieira RHF. Salmonella versus manipuladores de alimentos: Um fator de risco para os consumidores. Hig Aliment. 2000; 14(72):53-9.

30. Brasil. Agência Nacional de Vigilância Sanitária. Resolução RDC n²16, de 15 de setembro de 2004. Regulamento Técnico de Boas Práticas para Serviços de Alimentação. Diário Oficial da União. 2004; set 16.

Recebido em: 29/7/2008

Versão final reapresentada em: 14/4/2009 Aprovado em: 6/10/2009 